\title{
Bioelectrochemical production of hydrogen in an innovative pressure-retarded osmosis/microbial electrolysis cell system: experiments and modeling
}

\author{
Heyang Yuan ${ }^{1 \dagger}$, Yaobin Lu ${ }^{1 \dagger}$, Ibrahim M Abu-Reesh² and Zhen $\mathrm{He}^{1^{*}}$
}

\begin{abstract}
Background: While microbial electrolysis cells (MECs) can simultaneously produce bioelectrochemical hydrogen and treat wastewater, they consume considerable energy to overcome the unfavorable thermodynamics, which is not sustainable and economically feasible in practical applications. This study presents a proof-of-concept system in which hydrogen can be produced in an MEC powered by theoretically predicated energy from pressure-retarded osmosis (PRO). The system consists of a PRO unit that extracts high-quality water and generates electricity from water osmosis, and an MEC for organic removal and hydrogen production. The feasibility of the system was demonstrated using simulated PRO performance (in terms of energy production and effluent quality) and experimental MEC results (e.g., hydrogen production and organic removal).
\end{abstract}

Results: The PRO and MEC models were proven to be valid. The model predicted that the PRO unit could produce $485 \mathrm{~mL}$ of clean water and $579 \mathrm{~J}$ of energy with $600 \mathrm{~mL}$ of draw solution ( $0.8 \mathrm{M}$ of $\mathrm{NaCl}$ ). The amount of the predicated energy was applied to the MEC by a power supply, which drove the MEC to remove $93.7 \%$ of the organic compounds and produce $32.8 \mathrm{~mL}$ of $\mathrm{H}_{2}$ experimentally. Increasing the PRO influent volume and draw concentration could produce more energy for the MEC operation, and correspondingly increase the MEC hydraulic retention time (HRT) and total hydrogen production. The models predicted that at an external voltage of $0.9 \mathrm{~V}$, the MEC energy consumption reached the maximum PRO energy production. With a higher external voltage, the MEC energy consumption would exceed the PRO energy production, leading to negative effects on both organic removal and hydrogen production.

Conclusions: The PRO-MEC system holds great promise in addressing water-energy nexus through organic removal, hydrogen production, and water recovery: (1) the PRO unit can reduce the volume of wastewater and extract clean water; (2) the PRO effluents can be further treated by the MEC; and (3) the osmotic energy harvested from the PRO unit can be applied to the MEC for sustainable bioelectrochemical hydrogen production.

\section{Background}

Microbial electrolysis cells (MECs) is an attractive technology that can simultaneously remove organics and produce hydrogen gas. In MECs, exoelectrogens growing on

\footnotetext{
*Correspondence: zhenhe@vt.edu

${ }^{\dagger}$ Heyang Yuan and Yaobin Lu contributed equally.

1 Department of Civil and Environmental Engineering, Virginia

Polytechnic Institute and State University, Blacksburg, VA 24061, USA

Full list of author information is available at the end of the article
}

the anode respire by releasing electrons extracellularly; driven by an external voltage $>0.2 \mathrm{~V}$, those electrons flow to the cathode to reduce protons into hydrogen gas [1]. MECs are of strong interests because its energy consumption could be significantly lower than that of conventional methods such as water-splitting and steam reforming [2, 3]. Life cycle assessment suggested that MECs might outperform the prevailing wastewater treatment methods (i.e. activated sludge process and anaerobic digestion) in terms of energy requirement, greenhouse gas effect 
and other environmental impacts $[4,5]$. However, the requirement of additional energy, which is mostly from fossil fuels, should be further addressed to make MECs more sustainable.

Researchers have explored alternative energy sources to drive hydrogen production in MECs. For example, a microbial fuel cell (MFC) was used to replace external power supply and provided a voltage to achieve a hydrogen production rate of $0.015 \mathrm{~m}^{3} \mathrm{~m}^{-3} \mathrm{~d}^{-1}$ in an MFCMEC coupled system [6]. It was found that the hydrogen yield was relatively low and also instable in this coupled system, possibly due to cell voltage reversal between the two bioelectrochemical systems (BES). To avoid voltage reversal, a capacitor circuit was installed between MFCs and an MEC, and helped achieve $38 \%$ higher hydrogen production rate compared to the directly coupled system [7]. In another study, solar energy was harvested by a dyesensitized solar cell and then applied on an MEC, which achieved a hydrogen production rate of $0.07 \mathrm{~m}^{3} \mathrm{~m}^{-3} \mathrm{~d}^{-1}$ [8]. The entropic energy stored in a salinity gradient between seawater and fresh water is estimated to be $0.8 \mathrm{~kW} \mathrm{~m}^{-3}[9,10]$, which could be captured by reverse electrodialysis and then used to drive MECs [11-13].

Unlike salinity energy that relies on salt movement, osmotic energy can be produced through water interaction between saline water and freshwater, and can be harvested by using pressure-retarded osmosis (PRO). In a PRO system, water is driven by the salinity gradient and diffuses from a low-salinity solution (feed) to a high-salinity solution (draw) through a semi-permeable membrane; consequently, electrical energy is generated by pressurizing the diluted draw (whose volume becomes larger after water extraction) through a hydroturbine [14]. As a forward osmosis (FO) process, PRO shows low fouling propensity compared to reverse osmosis because of relatively low water flux and hydraulic pressure [15]. The recent advances in membrane technology could greatly reduce the capital cost of PRO and thus make it competitive with other renewable energy technologies [16]. The highest power density produced by PRO was reported to be $10.6 \mathrm{~W} \mathrm{~m}^{-2}$ with $1 \mathrm{M} \mathrm{NaCl}$ solution as draw [17].

We have previously integrated osmotic processes with BES to assist with bioelectricity generation in MFCs or desalination in microbial desalination cells (MDCs) [18]. For example, the first osmotic microbial fuel cell (OsMFC) was developed by replacing the ion exchange membrane with a FO membrane, and accomplished simultaneous wastewater treatment, water extraction, and bioenergy production [19]. The performance of an OsMFC was affected by its draw solution, membrane condition, anode substrates, and cathode reactions [2022]. The osmotic process was integrated with MDCs in several ways: replacement of anion exchange membrane with an FO membrane to create an osmotic MDC, linking an OsMFC with an MDC, or connecting an FO to an MDC [23-25]. Those prior studies have demonstrated the synergy between BES and FO, and provided a foundation for the present study.

Given the fact that PRO can generate electric energy and MECs need additional energy for hydrogen production, a PRO-MEC system is proposed here: wastewater (feed) and seawater (draw) flow into a PRO unit for water extraction and energy generation; then, the energy is applied to an MEC for organic removal and hydrogen production, with the PRO feed and draw effluents serving as the anolyte and the catholyte of the MEC, respectively (Fig. 1). This is the first time that the PRO energy (osmotic-to-electricity) is studied to drive the conversion of organic compounds to hydrogen in an MEC; in addition to electrical interaction between the two components, this system also contains hydraulic linkage between the two for wastewater treatment and reuse and saline water desalination. After further desalination, the produced water (diluted draw solution) could be useful for non-potable applications such as agricultural irrigation and landscaping. The system may have application niches in a location with seawater and a high demand for wastewater reuse.

To examine the proposed system, we first developed a time-dependent PRO model and a batch-mode MEC model. According to the simulated water flux obtained from the PRO model, the anolyte and the catholyte were prepared for an MEC that was operated experimentally using a power supply to mimic the energy supply process. The system feasibility was demonstrated by comparing the simulated PRO energy production and the experimental MEC energy consumption, together with other parameters such as water extraction, organics removal

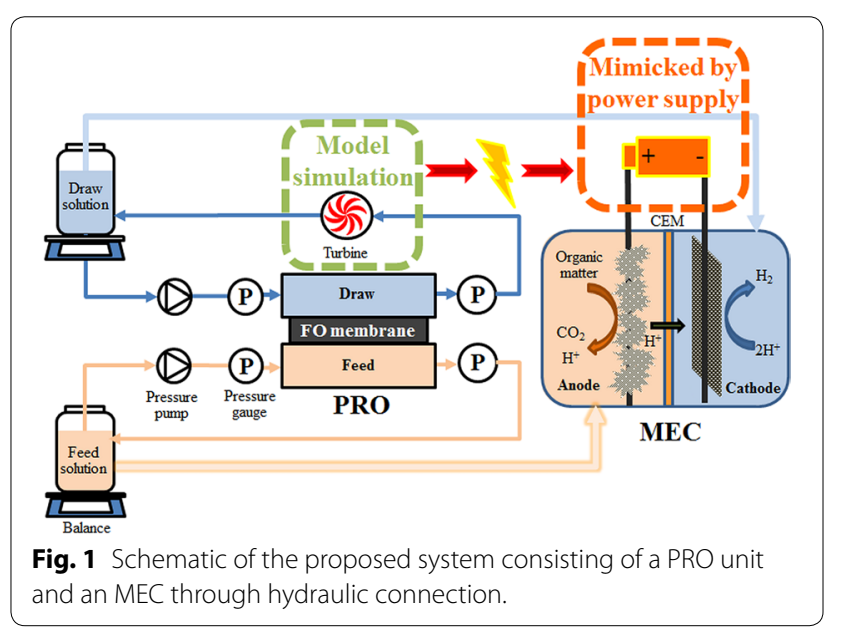


and hydrogen production. Finally, the PRO and MEC models were used to predict the system performance at varied influent volume, draw concentration and external voltage.

\section{Results and discussion Model validation}

Mathematical modeling can help understand the key factors in the PRO-MEC system and predict the behaviors that cannot be easily investigated by experiments. Previous PRO studies focused on achieving instantaneous maximum energy production, and it was not necessary to take the concentration change of the feed and the draw into account because of the constant replenishment of fresh solutions to maintain high osmotic pressure difference $[26,27]$. However, that is not applicable to a PROMEC system, because the relatively fast PRO process will generate excessive amount of effluent that can exceed the treating capacity of bench-scale MECs. In this regard, the PRO unit must be operated under a batch mode and the time variable must be introduced in the PRO model to predict the water flux and energy production. To examine that hypothesis, the PRO unit was operated for $6.0 \mathrm{~h}$ at different hydraulic pressures (1, 2 and 3 bar) with the initial conditions listed in Table 1 . At 1 bar, the feed solution decreased from $600 \mathrm{~mL}$ to $138 \mathrm{~mL}$ ( $462 \mathrm{~mL}$ of water recovery) with significant decrease in water flux (Additional file 1). The experiments at 2 and 3 bar showed similar trends, but with slightly lower water recovery due to the higher hydraulic pressure (Additional file 1). With the PRO parameters listed in the Additional file 2, the timedependent PRO model successfully predicted the volume profile with RMSE less than $2.5 \%$ (Table 2). The experiments with different $\mathrm{NaCl}$ concentrations $(0.5$ and $2.0 \mathrm{M})$ at 1 bar were conducted to further validate the model.
After 5.0-h operation, the feed volume decreased from $600 \mathrm{~mL}$ to $452 \mathrm{~mL}$ with $0.5 \mathrm{M}(148 \mathrm{~mL}$ water recovery, Additional file 3), $65 \%$ lower than that with $0.8 \mathrm{M}$ at the same operation time because of the lower osmotic pressure difference between the feed and the draw. On the other hand, water recovery rapidly reached $315 \mathrm{~mL}$ in 2.0 h with $2.0-\mathrm{M} \mathrm{NaCl}$ solution (Additional file 3). The results collectively demonstrated that the time-dependent PRO simulation agreed well with the experimental data (Table 2).

Based on the method presented in previous studies of MDC and MEC modeling [28, 29], a batch-mode MEC model was implemented with independent experiments of varied substrate and external resistance. The introduction of $\left[\mathrm{HCO}_{3}^{-}\right]$and $\left[\mathrm{H}^{+}\right]$into the anode potential (Eqs. 14, 15) and the substrate change in the concentration overpotential (Eq. 17) helped achieve satisfactory agreement between the experimental and simulation results. The RMSE for the MEC model (Table 2) was relatively high mainly due to the overestimation of organics removal (99.9\% removal) at the end of the MEC process. Consequently, at $0.8 \mathrm{~V}$, the model yielded slightly higher energy consumption (488 J) and hydrogen production $(36.7 \mathrm{~mL}$ ) compared to the experiments $(470 \mathrm{~J}$ and $32.8 \mathrm{~mL}$ ). The MEC's operation time was prolonged from $19.2 \mathrm{~h}$ at $357 \mathrm{mg} \mathrm{L}^{-1}$ acetate to $96.1 \mathrm{~h}$ at $2,007 \mathrm{mg} \mathrm{L}^{-1}$ acetate (Additional file 4). When the external voltage was increased, the current was improved from $2.7 \mathrm{~mA}$ at $0.6 \mathrm{~V}$ to $6.6 \mathrm{~mA}$ at $1.0 \mathrm{~V}$ (Additional file 4) with $60 \%$ increase in Coulombic efficiency and $40 \%$ increase in cathodic efficiency (Table 3). As a result, both hydrogen production and energy consumption increased by two times. The experimental results are consistent with previous studies [30]. In summary, the simulated current generation under different conditions could match the

Table 1 The initial conditions for the PRO experiments and simulation in different studies

\begin{tabular}{|c|c|c|c|c|c|c|c|c|}
\hline Experiment & $\mathrm{V}_{\mathrm{PRO}}^{\mathrm{a}}(\mathrm{mL})$ & $\mathrm{S}_{\mathrm{PRO}}^{\mathrm{b}}\left(\mathrm{mg} \mathrm{L}^{-1}\right)$ & $\mathrm{NaCl}_{\mathrm{In}}^{\mathrm{c}}(\mathrm{M})$ & $\mathrm{P}^{\mathrm{d}}$ (bar) & $V_{A}^{e}(m L)$ & $\mathrm{V}_{\mathrm{C}}^{\mathrm{f}}(\mathrm{mL})$ & $\begin{array}{l}S_{A}^{g} \\
\left(\mathrm{mg} \mathrm{L}^{-1}\right)\end{array}$ & Voltage $^{h}(V)$ \\
\hline Exp1-model validation & 600 & 193 & $0.5,0.8$ and 2.0 & 1,2 and 3 & 115 & 1,085 & $357,1,006$ and 2,007 & $0.6,0.8$ and 1 \\
\hline Exp2-system feasibility & 600 & 193 & 0.8 & $P_{t}$ & 115 & 1,085 & 1,007 & 0.8 \\
\hline Exp3-PRO influent volume & $100-2,000$ & 193 & 0.8 & $P_{t}$ & \multirow{2}{*}{\multicolumn{3}{|c|}{$\begin{array}{l}\text { Obtained from the time-dependent PRO } \\
\text { model }\end{array}$}} & 0.8 \\
\hline Exp4- $\mathrm{NaCl}$ concentration & 600 & 193 & $0.1-2.0$ & $P_{t}$ & & & & 0.8 \\
\hline Exp5-external voltage & 600 & 193 & 0.8 & $P_{t}$ & 115 & 1,085 & 1,007 & $0.5-1.1$ \\
\hline
\end{tabular}

\footnotetext{
a Volume of PRO feed and draw influent.

b Substrate concentration in the PRO feed influent.

c $\mathrm{NaCl}$ concentration in the PRO draw influent.

d Hydraulic pressure applied on the PRO draw chamber.

e Volume of MEC anolyte influent.

${ }^{f}$ Volume of MEC catholyte influent.

$g$ Substrate concentration in the MEC anolyte influent.

h External voltage applied on the MEC.
} 
Table 2 RMSE for the PRO and MEC simulation

\begin{tabular}{ll}
\hline & RMSE (\%) \\
\hline PRO & \\
1 bar-feed & $1.8 \pm 0.3$ \\
1 bar draw & $0.8 \pm 0.0$ \\
2 bar-feed & $1.9 \pm 0.6$ \\
2 bar draw & $0.8 \pm 0.0$ \\
3 bar-feed & $0.9 \pm 0.1$ \\
3 bar draw & $2.4 \pm 0.6$ \\
$0.5 \mathrm{M}$ feed & $1.9 \pm 0.2$ \\
$0.5 \mathrm{M}$ draw & $0.9 \pm 0.0$ \\
$2.0 \mathrm{M} \mathrm{feed}^{2}$ & $1.4 \pm 0.3$ \\
MEC $\mathrm{M}$ draw & $0.8 \pm 0.0$ \\
$0.6 \mathrm{~V}$ & \\
$0.8 \mathrm{~V}$ & $16.5+5.6$ \\
$1.0 \mathrm{~V}$ & $13.0 \pm 2.3$ \\
$357 \mathrm{mg} \mathrm{L}^{-1}$ & $23.6+1.3$ \\
$2,007 \mathrm{mg} \mathrm{L}^{-1}$ & 12.1 \\
\hline
\end{tabular}

The RMSE of the PRO model was calculated using the feed volume, and that of the MEC model was calculated using electricity.

Standard deviation was calculated with triplicate experiments.

experimental data, with slight overestimation of organics removal, energy consumption and hydrogen production.

\section{System feasibility}

The feasibility of the PRO-MEC system was demonstrated by estimating energy production in the PRO unit using the models and applying the energy (mimicked by a power supply) to the MEC for hydrogen production and organic removal. It should be noted that, because of the difficulty in generating real energy from bench-scale PRO units at a high hydraulic pressure, the majority of the PRO studies or publications adopted theoretical estimate of energy production [31-34]. The results showed that the PRO unit could theoretically generate sufficient energy to drive the MEC, which successfully produced hydrogen gas and removed more than $90 \%$ of organic compounds. In more details, the PRO simulation was performed at the hydraulic pressure of $P_{t}=\left(\pi_{D, t}-\pi_{F, t}\right) / 2$ (Eq. 7, at the maximum energy mode), and was stopped when water flux dropped below $0.5 \mathrm{LMH}\left(\mathrm{L} \mathrm{m}^{-2} \mathrm{~h}^{-1}\right)$. This was because that after $14.5 \mathrm{~h}$ of simulation, $P_{t}$ decreased to 2.4 bar and both the volume and the energy production reached a plateau (Fig. 2a). At the end of the simulation, the volume of the feed solution decreased from the initial $600 \mathrm{~mL}$ to $115 \mathrm{~mL}$ and the draw volume increased to $1085 \mathrm{~mL}$, suggesting that $485 \mathrm{~mL}$ of clean water was extracted from the feed solution. Meanwhile, the PRO unit could produce a feed effluent containing $1,007 \mathrm{mg} \mathrm{L}^{-1}$ acetate, a draw effluent with $0.46 \mathrm{M} \mathrm{NaCl}$, and $579 \mathrm{~J}$ of energy (Table 1; Fig. 2a).

Based on those results obtained from the PRO simulation, $115 \mathrm{~mL}$ of anolyte with $1,009 \pm 8 \mathrm{mg} \mathrm{L}^{-1}$ acetate and $1,085 \mathrm{~mL}$ of the catholyte with the $0.46 \mathrm{M} \mathrm{NaCl}$ were prepared and supplied to the MEC (Table 1). An external voltage of $0.8 \mathrm{~V}$ was applied to the MEC to mimic the utilization of the energy produced by the PRO unit. The MEC operating time was determined by equating the PRO energy production with the MEC energy consumption (Eqs. 8 and 19). The MEC current decreased steadily over time (Fig. 2b), mainly due to the consumption of organic compounds. At the end of the experiment, the MEC removed $93.7 \%$ of the organics and produced $32.8 \mathrm{~mL}$ of $\mathrm{H}_{2}$ at the expense of $470 \mathrm{~J}$ of energy after $46.9 \mathrm{~h}$ (Table 3 ), indicating that the energy produced by the PRO unit (579 J) was sufficient to drive the MEC. The relatively low hydrogen production rate $\left(0.016 \mathrm{~m}^{3}\right.$ $\mathrm{m}^{-3} \mathrm{~d}^{-1}$ ) and cathodic efficiency (48.1\%) was probably because no buffer was added in the catholyte (the $\mathrm{pH}$ increased from neutral to 11.6 after $3.0 \mathrm{~h}$ of operation). Coulombic efficiency (57.5\%) was comparable with other MECs, likely benefited from a relatively high organics concentration and conductivity of the anolyte, which was the concentrated feed solution from the PRO unit.

Table 3 The MEC performance at different external voltage

\begin{tabular}{|c|c|c|c|c|c|c|c|c|c|}
\hline Voltage (V) & $\mathrm{S}_{\ln }^{\mathrm{a}}\left(\mathrm{mg} \mathrm{L}^{-1}\right)$ & $C_{\ln }^{b}\left(\mathrm{mS} \mathrm{cm}^{-1}\right)$ & $\mathrm{V}_{\mathrm{H} 2}^{\mathrm{c}}(\mathrm{mL})$ & Rate $_{\mathrm{H} 2}\left(m^{3} m^{-3} d^{-1}\right)$ & $\Delta S^{d}(\%)$ & $\mathbf{R}_{\mathrm{CE}}^{\mathrm{e}}(\%)$ & $\mathrm{R}_{\text {cat }}^{\mathrm{f}}(\%)$ & Energy $(J)$ & HRT (h) \\
\hline & & $19.5 \pm 0.8$ & & & $95.6 \pm 0.0$ & $36.1 \pm 0.0$ & $42.9 \pm 0.0$ & $221 \pm 7$ & $54.4 \pm 2.3$ \\
\hline 0.8 & $1,009 \pm 8$ & $18.3 \pm 0.1$ & $32.8 \pm 0.6$ & $0.016 \pm 0.001$ & $93.7 \pm 0.0$ & $57.5 \pm 0.0$ & $48.1 \pm 0.0$ & $470 \pm 2$ & $46.9 \pm 1.4$ \\
\hline 1.0 & $987 \pm 53$ & $19.9 \pm 1.5$ & $40.8 \pm 2.8$ & $0.030 \pm 0.005$ & $94.7 \pm 0.0$ & $58.3 \pm 0.0$ & $60.7 \pm 0.1$ & $581 \pm 22$ & $30.9 \pm 3.2$ \\
\hline
\end{tabular}

Standard deviation was calculated with triplicate experiments.

a Substrate concentration in the MEC influent.

b Conductivity of the MEC influent.

c Total $\mathrm{H}_{2}$ production.

d Organics removal.

e Coulombic efficiency.

${ }^{f}$ Cathodic efficiency. 

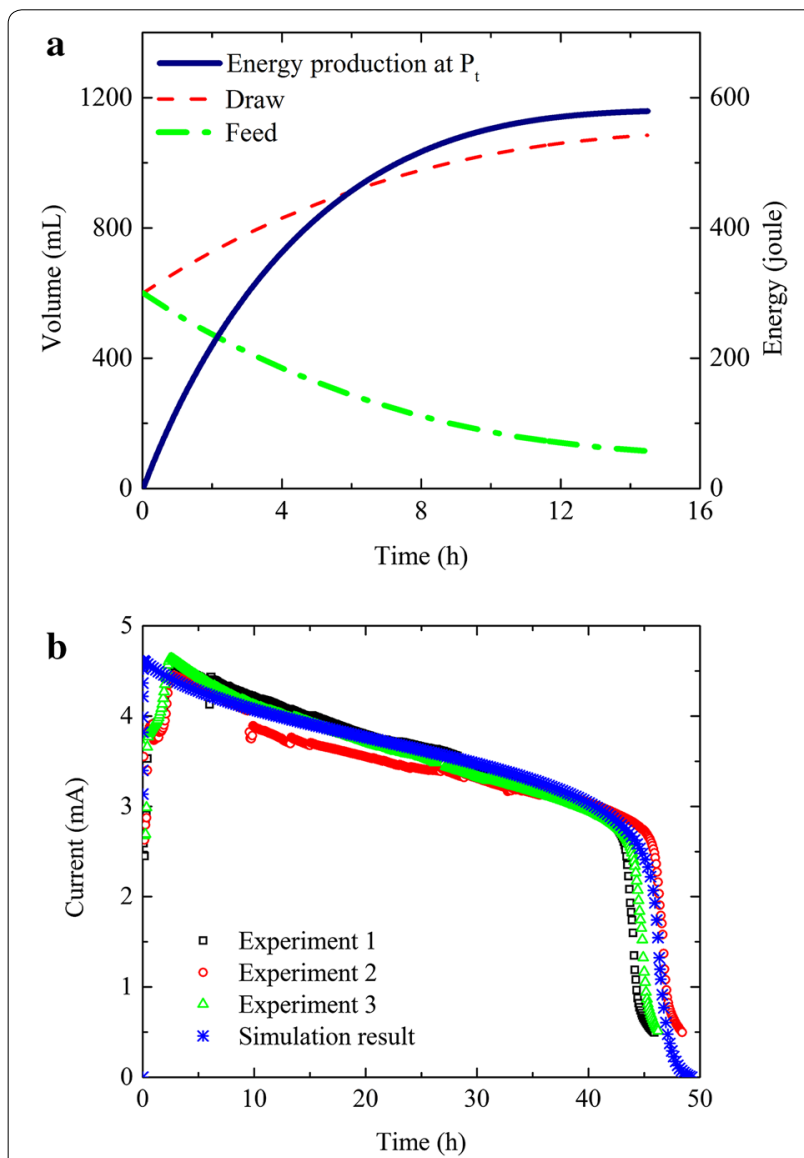

Fig. 2 a Volume profile and energy production in the PRO unit at the hydraulic pressure $P_{t}=\left(\pi_{D, t}-\pi_{F, t}\right) / 2$; b experimental data and simulation result of current generation in the MEC at $0.8 \mathrm{~V}$ using electrolyte and energy produced by the PRO unit.

Similar to the substrate concentration, the conductivity in the feed was concentrated by 5.2 times due to water extraction in the PRO unit, resulting in an initial conductivity of $18.3 \mathrm{mS} \mathrm{cm}^{-1}$ in the MEC anolyte. All those results have demonstrated that it is possible to harvest osmotic energy in the PRO unit and use it to convert chemical energy into hydrogen gas in the MEC from the same organic solution. In addition, the coupling of PRO and MEC can simultaneously recover clean water and reduce the volume of the organic solution.

\section{Model prediction}

\section{Effects of PRO influent volume}

In theory, the osmotic pressure difference will be less affected by the water flux at larger volumes of the feed and the draw solutions, leading to a prolonged PRO process and more energy available for driving the MEC. This hypothesis was examined with the PRO influent volume varied from 100 to $2,000 \mathrm{~mL}$ (simultaneous change in both the feed and the draw volumes), with other parameters listed in the Table 1 and $0.5 \mathrm{LMH}$ as a simulation end-point. The PRO simulation shows that both water recovery and energy production are enhanced by increasing the PRO influent volume, while the substrate concentration in the feed effluent remains stable (Fig. 3a, b). At the PRO influent of $1,000 \mathrm{~mL}, 794 \mathrm{~mL}$ of clean water is recovered and $949 \mathrm{~J}$ of energy is produced. These values are increased by two times with $2,000 \mathrm{~mL}$ of PRO influent. As the initial substrate concentration in the PRO feed influent remains unchanged $\left(193 \mathrm{mg} \mathrm{L}^{-1}\right)$, increasing the PRO influent volume leads to a higher total organic content in the MEC anolyte, which prolongs the MEC's HRT but does not exert effects on the maximum current (4.5 mA, Fig. 3c). As a result of the increased organics and HRT, hydrogen production is improved consistently. It is predicted that the PRO-MEC system produces $59 \mathrm{~mL}$ of $\mathrm{H}_{2}$ in $77.7 \mathrm{~h}$ with $1,000 \mathrm{~mL}$ of the PRO influent, and $92 \mathrm{~mL}$ of $\mathrm{H}_{2}$ in $121.2 \mathrm{~h}$ with $2,000 \mathrm{~mL}$ of the PRO influent (Fig. 3d). Interestingly, the energy consumption by the MEC increases non-linearly with increased PRO influent volume, resulting in an enlarged energy surplus between PRO unit and MEC (Fig. 3b). This is indicative that one PRO unit can drive multiple MECs at large volume loading, thereby further enhancing the overall treating capacity of the PRO-MEC system.

\section{Effects of $\mathrm{NaCl}$ concentration in the PRO draw influent}

The $\mathrm{NaCl}$ concentration ranging from 0.1 to $2.0 \mathrm{M}$ is input in the time-dependent PRO model with other parameters summarized in the Table 1 and $0.5 \mathrm{LMH}$ as simulation end-point. It is predicted that the water recovery is enhanced significantly when the $\mathrm{NaCl}$ concentration increases from 0.1 to $0.7 \mathrm{M}$, and further increase in the $\mathrm{NaCl}$ concentration does not result in continuing improvement of water recovery (Fig. 4a). On the other hand, both the energy production and the effluent substrate concentration increase linearly with the increased $\mathrm{NaCl}$ concentration (Fig. 4a, b). The PRO's HRT reaches the maximum of $20.8 \mathrm{~h}$ at $0.4 \mathrm{M}$, and then decreases readily to $9.2 \mathrm{~h}$ at $2.0 \mathrm{M}$ (Fig. $4 \mathrm{~b}$ ), likely because high water flux at a higher draw concentration causes faster decline in the osmotic pressure difference as described by Eqs. 5 and 6. When the $\mathrm{NaCl}$ concentration is lower than $0.7 \mathrm{M}$, the PRO energy production is predicted to be lower than the MEC energy consumption if the substrate is completely degraded (Fig. 4b). Therefore, the MEC performance is limited by the energy supply with low $\mathrm{NaCl}$ concentrations, and both the organics removal and hydrogen production cannot be performed effectively (below $93.0 \%$ and $34.2 \mathrm{~mL}$, respectively, Fig. 4c). When the $\mathrm{NaCl}$ concentration is higher than $0.8 \mathrm{M}$, sufficient electrical energy is generated in the PRO unit to support a complete MEC cycle with organics removal $>99 \%$. 


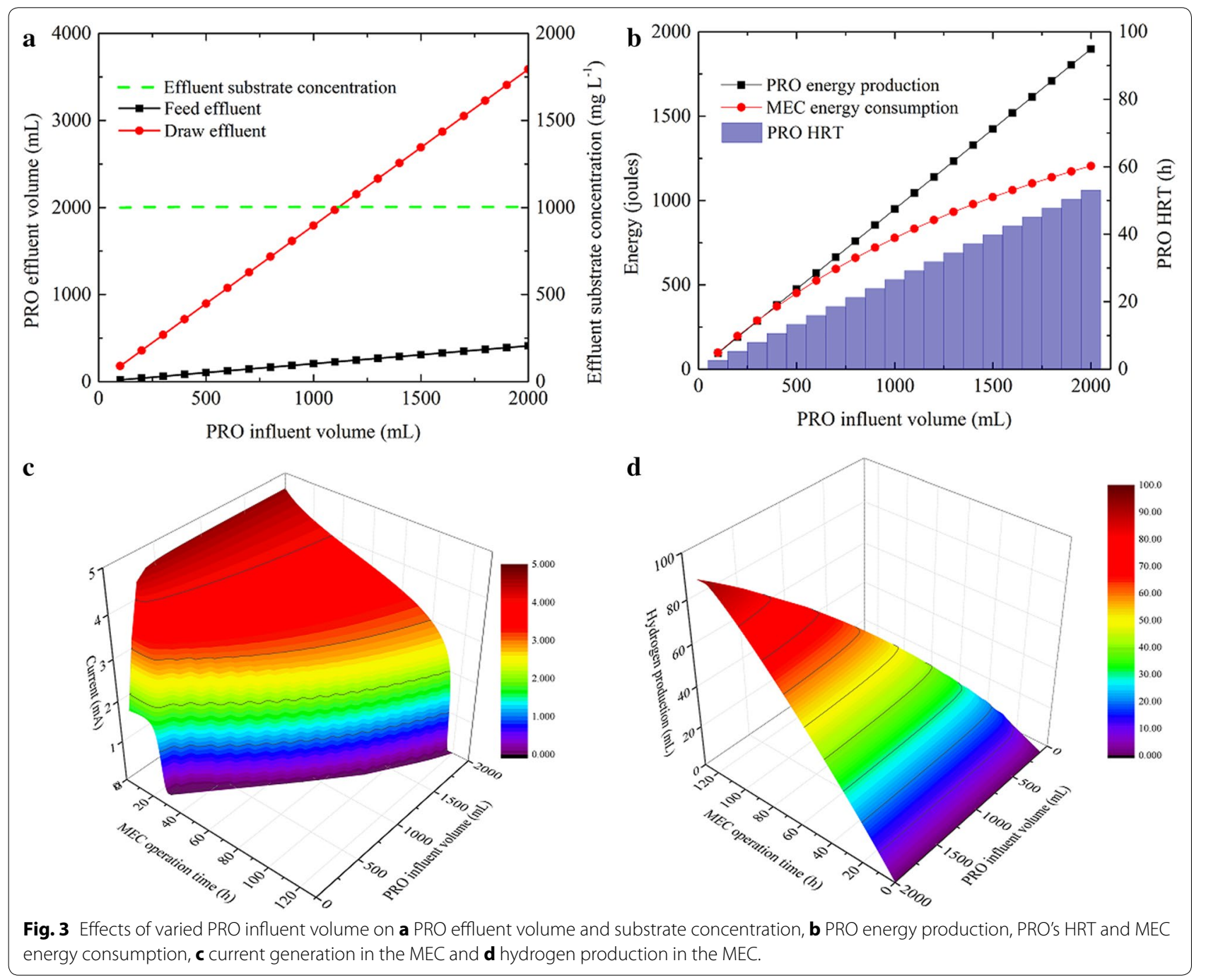

Consequently, the MEC's operating time is prolonged to over $50.7 \mathrm{~h}$, and the hydrogen production reaches $37.6 \mathrm{~mL}$. Further increase in the $\mathrm{NaCl}$ concentration beyond $1.5 \mathrm{M}$ does not noticeably enhance the hydrogen production, suggesting that the total organic content may have become a limiting factor for the MEC performance.

\section{Effects of external voltage on the MEC}

The energy consumption by the MEC is affected by the externally applied voltage according to Eqs. 18 and 19 . MEC simulation is therefore performed with external voltage varying from 0.5 to $1.1 \mathrm{~V}$. The initial conditions for the MEC simulation are listed in Table 1. The results show that at $0.5 \mathrm{~V}$, the MEC needs $89 \mathrm{~J}$ of energy to remove organics, but generates only $10.7 \mathrm{~mL} \mathrm{H}_{2}$ in $68.8 \mathrm{~h}$ (Fig. 5). The hydrogen production reaches the maximum value of $38.1 \mathrm{~mL}$ in $42.9 \mathrm{~h}$ at $0.9 \mathrm{~V}$, and declines at a higher external voltage. That is because the MEC energy consumption exceeds the PRO energy production: the PRO energy production with given input parameters is fixed (i.e. 579 J, Fig. 5 inset, red dash line), and at $1.0 \mathrm{~V}$ (or $1.1 \mathrm{~V}$ ), the MEC simulation is stopped once the energy consumption reaches $579 \mathrm{~J}$; as a result, the MEC cannot accomplish a complete cycle and hydrogen production would decrease because of a shorter operating time. The organic removal is predicted to be $92.7 \%$ at $1.0 \mathrm{~V}$ and only $80.3 \%$ at $1.1 \mathrm{~V}$. Meanwhile, the MEC's HRT is significantly shortened at a higher external voltage. These results indicate that the coupled system is versatile towards different purposes, and the treating capacity of the PRO and MEC can be balanced through varying external voltage.

\section{Perspectives}

The coupled PRO-MEC system can achieve multiple benefits. Firstly, the PRO unit can serve as pre-treatment of 

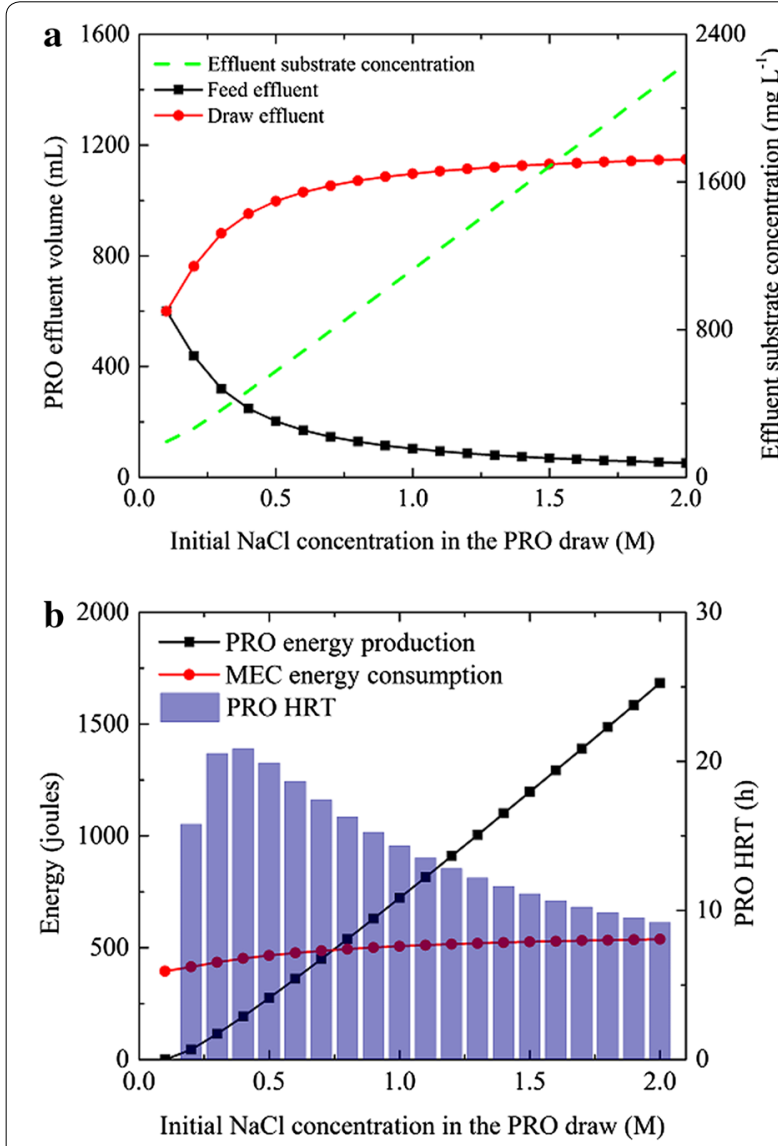

c

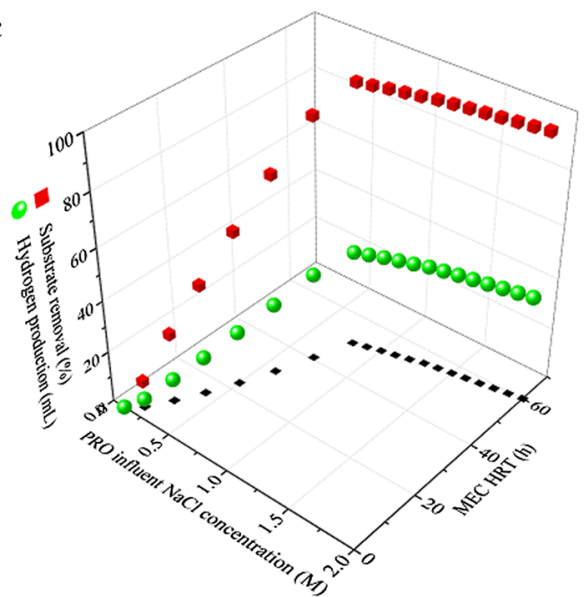

Fig. 4 Effects of varied $\mathrm{NaCl}$ concentration on a PRO effluent volume and substrate concentration, b PRO energy production, PRO's HRT and MEC energy consumption and $\mathbf{c}$ substrate removal and hydrogen production in the MEC.

organic solutions (e.g. wastewater), substantially reducing its volume and extracting clean water [15]. The draw solution for the PRO unit could be brine from RO desalination (91.3\% of water recovery predicted by the model)

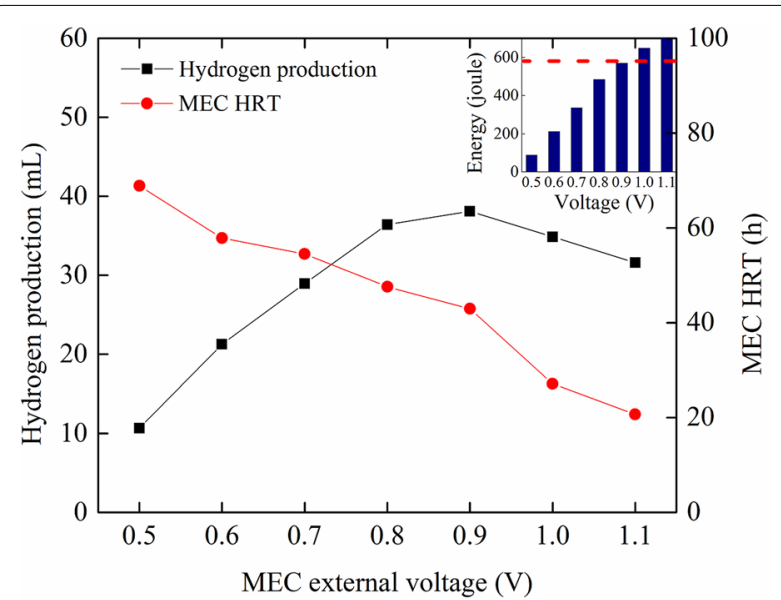

Fig. 5 Hydrogen production and MEC's HRT predicted by the batchmode MEC model with external voltage ranging from 0.5 to $1.1 \mathrm{~V}$. The inset shows the MEC energy consumption at different voltage and the red line indicates the PRO energy production.

or seawater (71.7\% water recovery). Secondly, the PRO process can generate a high-conductivity feed solution as the MEC anolyte, which decreases the electrolyte resistance and thus is beneficial for bioelectrochemical processes $[35,36]$. Thirdly, the osmotic energy harvested by the PRO process at certain influent volume and draw concentration is sufficient for a complete MEC cycle, making organic removal and hydrogen production more sustainable. Fourthly, compared with other approaches (e.g., MFC or solar energy) for driving hydrogen production in MECs, the present system can reduce the volume of the treated wastewater and produce a stream (diluted draw solution) for further desalination. For example, when seawater serves as a draw solution, its conductivity can be decreased from 54.7 to $32.0 \mathrm{mS} \mathrm{cm}^{-1}$ after the PRO process. Our previous study suggests that such a dilution can significantly enhance the rate of conductivity reduction in a microbial desalination cell [25].

Despite the great promise, several challenges must be addressed to move the PRO-MEC system towards practice. First, the robustness of the batch-mode MEC model should be improved by introducing endogenous respiration and more accurate $\mathrm{pH}$ variables [37, 38]. Because buffer was added in the feed/anolyte, the equilibrium between $\left[\mathrm{HCO}_{3}{ }^{-}\right]$and $\left[\mathrm{H}_{2} \mathrm{CO}_{3}\right]$ as a function of $\mathrm{pH}$ was not taken into account in this study. When real wastewater is used as a feed/anolyte, the equilibrium constant should be introduced in Eqs. 14 and 15. Moreover, the cathode potential in Eq. 16 could be modified by relating $\mathrm{pH}$ change to hydrogen production and the Fick's law of diffusion. Another critical issue for practical applications is to balance the treating capacity of PRO and MEC. The simulation results with a high PRO influent volume and 
a high draw concentration suggest that one PRO unit is able to generate surplus energy to drive multiple MECs. In addition, the disparity in HRTs between the PRO unit and the MEC should also be addressed with caution to optimize the efficiency when one PRO unit is coupled to several MECs. Finally, the proposed system needs to be further demonstrated with actual energy generated from a PRO unit, which was reported in only a few studies [39, 40].

\section{Conclusions}

This work has demonstrated a proof-of-concept PROMEC system for simultaneous bioelectrochemical hydrogen production, organic removal, and water extraction driven by two forms of energy generated from (theoretically) the same liquid stream. It also presents the first attempt to introduce time variable into a PRO model, and has modified the previous single-chamber MEC model into a two-chamber batch-mode MEC model. Multiple benefits can be achieved through the synergy between PRO and MEC, including sustainable hydrogen production, clean water recovery and reduced wastewater volume. A high influent volume and a high draw concentration are predicted to enhance the performance of the coupled system, and the optimal external voltage is determined to be $0.9 \mathrm{~V}$ by the models. The PRO-MEC system may hold great promise in addressing water-energy nexus.

\section{Methods}

\section{System setup and operation}

The experimental system consisted of a PRO unit and an MEC, as shown in Fig. 1. A forward osmosis (FO) cell (Sepa CF II Forward Osmosis Cell 316 SS, Sterlitech Corporation, USA) was used as the PRO unit, containing an FO membrane (HTI OsMem ${ }^{\mathrm{TM}}$ CTA-ES, Hydration Technology Innovations, USA) tailored to an area of $0.014 \mathrm{~m}^{2}$. The feed solution contained (per liter of deionized water): sodium acetate, $193 \mathrm{mg} ; \mathrm{NaCl}, 0.5 \mathrm{~g} ; \mathrm{MgSO}_{4}, 0.015 \mathrm{~g}$; $\mathrm{CaCl}_{2}, 0.02$ g; $\mathrm{KH}_{2} \mathrm{PO}_{4}, 1.06$ g; $\mathrm{K}_{2} \mathrm{HPO}_{4}, 2.14$ g; $\mathrm{NaHCO}_{3}$, $1 \mathrm{~g}$; and trace element, $1 \mathrm{~mL}$. A synthetic organic solution was used because it could be better controlled for organic concentrations and other parameters. The feed solution $\left(600 \mathrm{~mL}, \pi_{\mathrm{F}, 0}=2.4 \mathrm{bar}\right)$ was recirculated between a reservoir and the PRO feed chamber by a peristaltic pump (Langer Instruments Corp., USA) at a crossflow velocity of $16.4 \mathrm{~cm} \mathrm{~s}^{-1}$. The $\mathrm{NaCl}$ solution $(0.8 \mathrm{M}$, $600 \mathrm{~mL}, \pi_{\mathrm{D}, 0}=36.2 \mathrm{bar}$ ) was used as a draw and recirculated between a reservoir and the PRO draw chamber by a high pressure water pump (Estone $12 \mathrm{~V} \mathrm{DC} 5 \mathrm{~L} / \mathrm{min}$ $60 \mathrm{~W}$, China) at a cross-flow velocity of $85.9 \mathrm{~cm} \mathrm{~s}^{-1}$. Low hydraulic pressures (1,2 and 3 bar) were applied on the draw chamber of the PRO cell using a pressure valve at the outlet and monitored with two gauges at both inlet and outlet. The PRO unit was operated for $6.0 \mathrm{~h}$ as a batch, and the weight change in both feed and draw solutions was monitored by using digital balances (Scort Pro, Ohaus, USA).

A two-chamber MEC was built as previously described [41], with a carbon-brush anode electrode and a carboncloth cathode electrode that contained $5 \mathrm{mg} \mathrm{cm}^{-2}$ of $\mathrm{Pt} / \mathrm{C}$ and a surface area of $10 \mathrm{~cm}^{2}$. The anode was inoculated with anaerobic sludge from a local wastewater treatment plant (Peppers Ferry, Radford, VA, USA). The liquid volumes of the anode compartment and the cathode compartment of the MEC were equal at $140 \mathrm{~mL} / \mathrm{each}$. Those electrolytes were recirculated between the MEC and the external reservoirs. An external voltage of $0.8 \mathrm{~V}$ was applied on the MEC with a power supply (3644A, Circuit Specialists, Inc., USA) to mimic the utilization of the energy from the PRO unit. The electrolytes were prepared as shown in Table 1 and purged with nitrogen gas for 15 min prior to each test. The MEC was operated under a batch mode at room temperature. The operation time of the MEC was determined by equating the PRO energy production with the MEC energy consumption by assuming no energy loss during energy conversion process. In both the PRO and MEC experiments, triplicate experiments were conducted for each test condition. The system at different PRO influent volumes, $\mathrm{NaCl}$ concentrations and external voltages was evaluated with the time-dependent PRO model and the batch-mode MEC model.

\section{Measurement and analysis}

Weight change of the feed and draw solutions was recorded by an auto logging software (Scort Pro, Ohous, USA) at a time interval of $2 \mathrm{~min}$. Water flux was calculated as derivative of the volume change. Conductivity was measured by using a benchtop conductivity meter (Mettler-Toledo, USA). The voltage $(U)$ of the MEC on a resistor $(R=1 \Omega$, HARS-X-3_0.001, USA) was recorded by a digital multimeter (2700, Keithley Instruments, Inc., USA) at a time interval of $5 \mathrm{~min}$. The current was calculated according to Ohm's law: $i=U / R$. Hydrogen produced by the MEC was collected using water displacement method and the volume was measured with a syringe. COD was measured using a DR/890 colorimeter (HACH Co., Ltd., USA) according to manufacturer's instruction. Organics (acetate) concentration in the effluent was calculated by dividing the COD by the empirical coefficient of 0.78 . The $\mathrm{pH}$ was measured by a benchtop pH meter (Oakton Instruments, USA). Important MEC parameters were calculated as previously described [41]. Hydrogen production rate was calculated based on the catholyte volume, which was obtained from the PRO simulation. 


\section{Time-dependent PRO model}

The time-dependent water flux was simulated based on the PRO model developed by Yip et al. [27]:

$$
J_{t}=A\left\{\frac{\pi_{D, t} \exp \left(-\frac{J_{t}}{k}\right)-\pi_{F, t} \exp \left(\frac{J_{t} S}{D}\right)}{1+\frac{B}{J_{t}}\left[\exp \left(\frac{J_{t} S}{D}\right)-\exp \left(-\frac{J_{t}}{k}\right)\right]}-P_{t}\right\}
$$

where $J_{t}\left(\mathrm{~m}^{3} \mathrm{~m}^{-2} \mathrm{~s}^{-1}\right)$ is the instantaneous water flux at time $t, \pi_{D, t}$ and $\pi_{F, t}$ (bar) are the osmotic pressure of the bulk draw and feed solution at time $t$, respectively, $A\left(\mathrm{~m}^{3} \mathrm{~m}^{-2} \mathrm{~s}^{-1} \mathrm{bar}^{-1}\right)$ is the permeability coefficient, $B$ $\left(\mathrm{m}^{3} \mathrm{~m}^{-2} \mathrm{~s}^{-1}\right)$ is the salt permeability coefficient, $S(\mathrm{~m})$ is the support layer structural parameter, $D\left(\mathrm{~m}^{2} \mathrm{~s}^{-1}\right)$ is the diffusion coefficient of $\mathrm{NaCl}$ in the membrane substrate, $k\left(\mathrm{~m}^{3} \mathrm{~m}^{-2} \mathrm{~s}^{-1}\right)$ is the mass transfer coefficient, and $P_{t}$ (bar)is the hydraulic pressure applied on the draw chamber at time $t$. The real-time volume of the feed $\left(V_{F, t}\right)$ and draw $\left(V_{D, t}\right)$ are thus:

$$
\begin{aligned}
& V_{F, t}=V_{F, 0}-\int J_{t} d t \\
& V_{D, t}=V_{D, 0}+\int J_{t} d t
\end{aligned}
$$

where $V_{F, 0}$ and $V_{D, 0}(\mathrm{~L})$ are the initial feed and draw volume. The reverse salt flux $J_{S, t}\left(\mathrm{~mol} \mathrm{~m}^{-2} \mathrm{~s}^{-1}\right)$ can be approximated as [42]:

$$
J_{S, t}=\frac{B J_{t}}{A i R T}
$$

where $i$ is the number of dissolved species ( 2 for $\mathrm{NaCl}$ ), $R\left(8.3145 \mathrm{~J} \mathrm{~mol}^{-1} \mathrm{~K}^{-1}\right)$ is the ideal gas constant, and $T$ $(298.15 \mathrm{~K})$ is the absolute temperature. According to the van't Hoff equation: $\pi=i R T C$, where $C(\mathrm{M})$ is the molar concentration, the real-time osmotic pressure is obtained by combining Eqs. 1-4:

$$
\begin{aligned}
& \pi_{F, t}=i R T\left(\frac{V_{F, 0} C_{F, 0}+a \int J_{S, t} d t}{V_{F, t}}\right) \\
& \pi_{D, t}=i R T\left(\frac{\left.V_{D, 0} C_{D, 0}-a \int J_{S, t} d t\right)}{V_{D, t}}\right)
\end{aligned}
$$

where $a\left(0.014 \mathrm{~m}^{2}\right)$ is the membrane area, $C_{F, 0}(\mathrm{M})$ is the initial salt concentration in the feed solution obtained by multiplying the conductivity $\left(\mathrm{mS} \mathrm{cm}^{-1}\right)$ by the empirical coefficient of $0.64 \mathrm{ppm}$ and dividing the result by the molecular weight of $\mathrm{NaCl}\left(58.5 \mathrm{~g} \mathrm{~mol}^{-1}\right)$, and $C_{D, 0}(\mathrm{M})$ is the initial $\mathrm{NaCl}$ concentration. It can be derived from the expression of power density and ideal water flux that the maximum power is generated when $P=\left(\pi_{D}-\pi_{F}\right) / 2$ [16]. In order to maintain the maximum energy production
$Q_{P R O}$ (joule) during the PRO process, the instantaneous hydraulic pressure applied on the draw chamber in Eq. 1 is calculated as:

$$
\begin{gathered}
P_{t}=\frac{\left(\pi_{D, t}-\pi_{F, t}\right)}{2} \\
Q_{P R O}=a \int P_{t} J_{t} d t
\end{gathered}
$$

\section{Batch-mode MEC model}

The batch-mode MEC model was modified based on previously reported multi-population MEC model and MDC model $[28,29,43]$. Because acetate was used as substrate and the cathode chamber is abiotic, it was assumed that the anode biofilm was composed of acetoclastic methanogens and exoelectrogens. Moreover, the MEC was operated under a batch mode and thus the dilution rate used in the previous study is not applicable [28]. The mass balance for the substrate and the growth of the organisms can be written:

$$
\begin{aligned}
\frac{d S}{d t}= & -q_{e, \max } \frac{S}{K_{e}+S} \frac{M_{O X}}{K_{M}+M_{O X}} x_{e} \\
& -q_{m, \max } \frac{S}{K_{m}+S} x_{m} \\
\frac{d x_{e}}{d t}= & -\mu_{e, \max } \frac{S}{K_{e}+S} \frac{M_{O X}}{K_{M}+M_{O X}} x_{e}-d_{e} x_{e} \\
\frac{d x_{m}}{d t}= & -\mu_{m, \max } \frac{S}{K_{m}+S} x_{m}-d_{m} x_{m} \\
\frac{d M_{O X}}{d t} & =-Y_{M} \frac{S}{K_{e}+S} \frac{M_{O X}}{K_{M}+M_{O X}}+\frac{\gamma}{V_{a} x_{e}} \frac{I}{n F}
\end{aligned}
$$

where $S\left(\mathrm{mg}^{-S \mathrm{~L}^{-1}}\right)$ is the acetate concentration, $x_{e}$ and $x_{m}\left(\mathrm{mg}-\mathrm{x} \mathrm{L} \mathrm{L}^{-1}\right)$ are the concentrations of exoelectrogens and methanogens, respectively, $q_{e, \max }$ and $q_{\operatorname{m,max}}$ (mg-S mg- $\mathrm{x}^{-1}$ day $^{-1}$ ) are the maximum substrate consumption rates by organisms, $K_{e}, K_{m}$, and $K_{M}\left(\mathrm{mg}^{-\mathrm{S} \mathrm{L}^{-1}}\right.$, $\mathrm{mg}-\mathrm{S} \mathrm{L}^{-1}$, and $\mathrm{mg}-\mathrm{M} \mathrm{mg-x^{-1 }}$ ) are the half saturation concentrations for exoelectrogens, methanogens, and the redox mediators, respectively, $\mu_{e, \max }$ and $\mu_{\operatorname{m,max}}\left(\right.$ day $^{-1}$ ) are the maximum growth rates by the organisms, $d_{e}$ and $d_{m}\left(\right.$ day $\left.^{-1}\right)$ are the decay rates of the organisms, $M_{O X}$ $\left(\mathrm{mg}-\mathrm{M} \mathrm{mg}-\mathrm{x}^{-1}\right)$ is the fraction of oxidized mediators per exoelectrogen, $Y_{M}\left(\mathrm{mg}-\mathrm{M} \mathrm{mg}-\mathrm{S}^{-1}\right)$ is the mediator yield, $\gamma\left(\mathrm{mg}-\mathrm{M}\right.$ mole- $\left.\mathrm{M}^{-1}\right)$ is the mediator molar mass, $I$ (A) is the current through the circuit of the MEC, $F$ $\left(96,485 \mathrm{C} \mathrm{mol}^{-1}\right)$ is the Faraday constant, $n$ (2) is number of electrons transferred per mole of mediator, $V_{a}(\mathrm{~L})$ is the anolyte volume. The anode and cathode potential $E_{A}$ and $E_{C}(\mathrm{~V})$ are calculated with the Nernst equation [44]: 


$$
\begin{aligned}
& E_{A}=E_{A}^{0}-\frac{R T}{8 F} \operatorname{In} \frac{S}{\left[H C O_{3}^{-}\right]^{2}\left[H^{+}\right]^{9}} \\
& {\left[H C O_{3}^{-}\right]=\left[H C O_{3}^{-}\right]_{0} \frac{V_{F, 0}}{V_{F}}+\frac{2\left(S_{0}-S\right)}{m_{S}}} \\
& \frac{d\left[H^{+}\right]}{d t}=\frac{\beta}{m_{S}} \frac{d S}{d t}\left(9-8 \cdot C E \cdot Y_{H Z}\right) \\
& E_{C}=E_{C}^{0}-\frac{R T}{2 F} \operatorname{In} \frac{1}{\left(10^{-11}\right)^{2}}
\end{aligned}
$$

where $E_{A}^{0}(0.187 \mathrm{~V})$ is the standard reduction potential of $\mathrm{HCO}_{3}^{-} / \mathrm{CH}_{3} \mathrm{COOH}^{-}$and $E_{C}^{0}(0 \mathrm{~V})$ is the standard reduction potential of $\mathrm{H}^{+} / \mathrm{H}_{2},\left[\mathrm{HCO}_{3}{ }^{-}\right]_{0}(0.00012 \mathrm{M})$ is the initial bicarbonate concentration in the feed influent, $V_{F, O}$ and $V_{F}(\mathrm{~L})$ are the initial and final volume of the PRO feed, $S_{0}$ and $S\left(\mathrm{mg} \mathrm{L}^{-1}\right)$ are the initial and final acetate concentration in the PRO feed, $m_{S}\left(82 \mathrm{~g} \mathrm{~mol}^{-1}\right)$ is the molar weight of acetate, $\beta(\%)$ is the buffer efficiency of the anolyte, $C E(\%)$ is the coulombic efficiency and $Y_{H 2}$ (\%) is the cathodic efficiency. The rationale of Eq. 15 is that every mole of the acetate produces $9 \mathrm{~mol}$ of protons and $8 \mathrm{~mol}$ of electrons. With $8 C E$ moles of electrons being transferred to the cathode, $8 C E Y_{H_{2}}$ mol of protons migrate and diffuse to the cathode and are reduced to $\mathrm{H}_{2}$, leaving the residual protons to affect the anolyte $\mathrm{pH}$. The cathode potential is assumed to be stable and calculated with a $\mathrm{pH}$ value of $11\left(10^{-11}\right.$ in Eq. 16 as proton concentration) because no buffer is added in the draw solution/catholyte, and the $\mathrm{pH}$ increased from neutral to $11.64 \pm 0.02$ in the first $3 \mathrm{~h}$ and remained stable throughout the MEC experiments. At batch mode, the concentration overpotential $\eta_{\text {con }}(\mathrm{V})$ in the anode is determined by both the mediator concentration and the substrate concentration, and thus can be written:

$$
\eta_{\text {con }}=\frac{R T}{F} \operatorname{In} \frac{M_{\text {Total }}}{M_{\text {Total }}-M_{O X}} \frac{S_{0}}{S}
$$

where $M_{\text {Total }}\left(\mathrm{mg}-\mathrm{M} \mathrm{mg- \textrm {x } ^ { - 1 } )}\right.$ is the total mediator fraction per exoelectrogen. Combining Eqs. 13-17 yields the MEC current, the energy consumption $Q_{M E C}$ (joule) and the hydrogen production $V_{H 2}(\mathrm{~mL})$ :

$$
\begin{aligned}
& I=\frac{\left(E_{C}-E_{A}\right)+E_{\text {ext }}-\eta_{\text {con }}}{\mathrm{R}_{\text {ext }}+R_{\text {in }}} \frac{M_{\text {Total }}-M_{O X}}{\varepsilon+M_{\text {Total }}-M_{O X}} \\
& Q_{M E C}=E_{\text {ext }} \int I d t \\
& V_{H 2}=Y_{H 2} \frac{I}{2 F} \frac{R T}{P}
\end{aligned}
$$

where $E_{\text {ext }}(\mathrm{V})$ is the external voltage applied on the MEC, $R_{\text {ext }}(\Omega)$ is the external resistance, $\varepsilon\left(0.0001 \mathrm{mg}-\mathrm{M} \mathrm{mg- \textrm {x } ^ { - 1 } )}\right.$ is a constant from a previous study [43], $P(1 \mathrm{~atm})$ is the air pressure in the cathode and $R_{\text {in }}(\Omega)$ is the internal resistance [43]:

$$
R_{\text {in }}=R_{\text {min }}+\left(R_{\text {max }}-R_{\text {min }}\right) e^{-K_{R} x_{e}}
$$

where $R_{\text {min }}(\Omega)$ is the lowest observed internal resistance, $R_{\text {max }}(\Omega)$ is the highest observed internal resistance, and $K_{R}\left(\mathrm{~L} \mathrm{mg- \textrm {x } ^ { - 1 } )}\right.$ is the constant that determines the curve steepness.

\section{Parameter estimation}

The parameters were estimated as previously described and listed in the Additional file 2 [28]. The relative rootmean square error (RMSE) as a measure of the discrepancy between the experimental data and the simulation results was calculated:

$$
R M S E=\frac{\sqrt{\frac{\sum_{i=1}^{N}\left(y_{i}-\hat{y}_{i}\right)^{2}}{N}}}{\hat{y}_{i, \max }}
$$

where $N$ is the total sampling time points in the simulation; $\hat{y}_{i}$ and $y_{i}$ are experimental data and model predicted values at $t$, respectively; and $\hat{y}_{i, \max }$ is the maximum value of the experimental data. The RMSE of the PRO model was calculated using the feed volume, and that of the MEC model was calculated using electricity.

\section{Additional files}

Additional file 1: Experimental data and simulation results of draw (increase over time), feed volume (decrease over time) and water flux at (A) 1 bar, (B) 2 bar and (C) 3 bar.

Additional file 2: Parameters used in the time-dependent PRO model and batch-mode MEC model.

Additional file 3: Experimental data and simulation results of draw (increase over time), feed volume (decrease over time) and water flux with (A) 0.5 and (B) $2.0 \mathrm{M} \mathrm{NaCl}$.

Additional file 4: (A) Experimental data and simulation result of current generation in the MEC with 357 and $2007 \mathrm{mg} \mathrm{L}^{-1}$ substrate in the MEC anolyte, and at the external voltage of (B) 0.6 and (C) $1.0 \mathrm{~V}$.

\section{Abbreviations}

FO: forward osmosis; PRO: pressure-retarded osmosis; BES: bioelectrochemical systems; MEC: microbial electrolysis cell; MFC: microbial fuel cell; OsMFC: osmotic microbial fuel cell; MDC: microbial desalination cells; HRT: hydraulic retention time; $L M H: L m^{-2} h^{-1}$; RMSE: root-mean square error.

\section{Author's contributions}

$\mathrm{ZH}, \mathrm{HY}$, and $\mathrm{YL}$ designed and conceived this work. $H Y$ and $Y L$ performed the experiment. $H Y, Y L, Z H$, and IA performed the data analysis. $H Y, Y L, Z H$, and IA wrote the manuscript. All authors read and approved the final manuscript.

\section{Author details}

${ }^{1}$ Department of Civil and Environmental Engineering, Virginia Polytechnic Institute and State University, Blacksburg, VA 24061, USA. ${ }^{2}$ Department 
of Chemical Engineering, College of Engineering, Qatar University, P.O. Box 2713, Doha, Qatar.

\section{Acknowledgements}

The authors would like to thank Ms. Qingyun Ping (Virginia Tech) for her help with mathematical modeling. This work was made possible by NPRP grant \# 6-289-2-125 from the Qatar National Research Fund (a member of Qatar Foundation). The statements made herein are solely the responsibility of the authors.

\section{Compliance with ethical guidelines}

\section{Competing interests}

The authors declare that they have no competing interests.

Received: 23 June 2015 Accepted: 3 August 2015

Published online: 14 August 2015

\section{References}

1. Liu H, Grot S, Logan BE (2005) Electrochemically assisted microbial production of hydrogen from acetate. Environ Sci Technol 39:4317-4320

2. Ni M, Leung MKH, Leung DYC, Sumathy K (2007) A review and recent developments in photocatalytic water-splitting using for hydrogen production. Renew Sustain Energy Rev 11:401-425

3. Haryanto A, Fernando S, Murali N, Adhikari S (2005) Current status of hydrogen production techniques by steam reforming of ethanol: a review. Energ Fuels 19:2098-2106

4. Foley JM, Rozendal RA, Hertle CK, Lant PA, Rabaey K (2010) Life cycle assessment of high-rate Anaerobic treatment, microbial fuel cells, and microbial electrolysis cells. Environ Sci Technol 44:3629-3637

5. Heidrich ES, Dolfing J, Scott K, Edwards SR, Jones C, Curtis TP (2013) Production of hydrogen from domestic wastewater in a pilot-scale microbial electrolysis cell. Appl Microbiol Biotechnol 97:6979-6989

6. Sun M, Sheng G-P, Zhang L, Xia C-R, Mu Z-X, Liu X-W et al (2008) An MECMFC-coupled system for biohydrogen production from acetate. Environ Sci Technol 42:8095-8100

7. Hatzell MC, Kim Y, Logan BE (2013) Powering microbial electrolysis cells by capacitor circuits charged using microbial fuel cell. J Power Sour 229:198-202

8. Chae K-J, Choi M-J, Kim K-Y, Ajayi FF, Chang I-S, Kim IS (2009) A solarpowered microbial electrolysis cell with a platinum catalyst-free cathode to produce hydrogen. Environ Sci Technol 43:9525-9530

9. Yip NY, Elimelech M (2012) Thermodynamic and energy efficiency analysis of power generation from natural salinity gradients by pressure retarded osmosis. Environ Sci Technol 46:5230-5239

10. Logan BE, Elimelech M (2012) Membrane-based processes for sustainable power generation using water. Nature 488:313-319

11. Kim Y, Logan BE (2011) Hydrogen production from inexhaustible supplies of fresh and salt water using microbial reverse-electrodialysis electrolysis cells. Proc Natl Acad Sci USA 108:16176-16181

12. Cusick RD, Kim Y, Logan BE (2012) Energy capture from thermolytic solutions in microbial reverse-electrodialysis cells. Science 335:1474-1477

13. Nam J-Y, Cusick RD, Kim Y, Logan BE (2012) Hydrogen generation in microbial reverse-electrodialysis electrolysis cells using a heat-regenerated salt solution. Environ Sci Technol 46:5240-5246

14. Achilli A, Childress AE (2010) Pressure retarded osmosis: from the vision of Sidney Loeb to the first prototype installation-Review. Desalination 261:205-211

15. Lutchmiah K, Verliefde ARD, Roest K, Rietveld LC, Cornelissen ER (2014) Forward osmosis for application in wastewater treatment: a review. Water Res 58:179-197

16. Helfer F, Lemckert C, Anissimov YG (2014) Osmotic power with pressure retarded osmosis: theory, performance and trends - a review. J Membr Sci 453:337-358

17. Chou S, Wang R, Shi L, She Q, Tang C, Fane AG (2012) Thin-film composite hollow fiber membranes for pressure retarded osmosis (PRO) process with high power density. J Membr Sci 389:25-33
18. Lu Y, Qin M, Yuan H, Abu-Reesh I, He Z (2015) When bioelectrochemical systems meet forward osmosis: accomplishing wastewater treatment and reuse through synergy. Water 7:38-50

19. Zhang F, Brastad KS, He Z (2011) Integrating forward osmosis into microbial fuel cells for wastewater treatment, water extraction and bioelectricity generation. Environ Sci Technol 45:6690-6696

20. Werner CM, Logan BE, Saikaly PE, Amy GL (2013) Wastewater treatment, energy recovery and desalination using a forward osmosis membrane in an air-cathode microbial osmotic fuel cell. J Membr Sci 428:116-122

21. Ge Z, He Z (2012) Effects of draw solutions and membrane conditions on electricity generation and water flux in osmotic microbial fuel cells. Bioresour Technol 109:70-76

22. Ge Z, Ping Q, Xiao L, He Z (2013) Reducing effluent discharge and recovering bioenergy in an osmotic microbial fuel cell treating domestic wastewater. Desalination 312:52-59

23. Zhang B, He Z (2012) Integrated salinity reduction and water recovery in an osmotic microbial desalination cell. RSC Adv 2:3265-3269

24. Zhang B, He Z (2013) Improving water desalination by hydraulically coupling an osmotic microbial fuel cell with a microbial desalination cell. J Membr Sci 441:18-24

25. Yuan H, Abu-Reesh IM, He Z (2015) Enhancing desalination and wastewater treatment by coupling microbial desalination cells with forward osmosis. Chem Eng J 270:437-443

26. She $Q$, Jin $X$, Tang CY (2012) Osmotic power production from salinity gradient resource by pressure retarded osmosis: effects of operating conditions and reverse solute diffusion. J Membr Sci 401-402:262-273

27. Yip NY, Tiraferri A, Phillip WA, Schiffman JD, Hoover LA, Kim YC et al (2011) Thin-film composite pressure retarded osmosis membranes for sustainable power generation from salinity gradients. Environ Sci Technol 45:4360-4369

28. Ping Q, Zhang C, Chen X, Zhang B, Huang Z, He Z (2014) Mathematical model of dynamic behavior of microbial desalination cells for simultaneous wastewater treatment and water desalination. Environ Sci Technol 48:13010-13019

29. Pinto RP, Srinivasan B, Escapa A, Tartakovsky B (2011) Multi-population model of a microbial electrolysis cell. Environ Sci Technol 45:5039-5046

30. Tartakovsky B, Manuel MF, Wang H, Guiot SR (2009) High rate membraneless microbial electrolysis cell for continuous hydrogen production. Int J Hydro Energ 34:672-677

31. Song X, Liu Z, Sun DD (2013) Energy recovery from concentrated seawater brine by thin-film nanofiber composite pressure retarded osmosis membranes with high power density. Energy Environ Sci 6:1199-1210

32. Yip NY, Elimelech M (2014) Comparison of energy efficiency and power density in pressure retarded osmosis and reverse electrodialysis. Environ Sci Technol 48:11002-11012

33. Straub AP, Lin S, Elimelech M (2014) Module-scale analysis of pressure retarded osmosis: performance limitations and implications for full-scale operation. Environ Sci Technol 48:12435-12444

34. Prante JL, Ruskowitz JA, Childress AE, Achilli A (2014) RO-PRO desalination: an integrated low-energy approach to seawater desalination. Appl Energy 120:104-114

35. Yossan S, Xiao L, Prasertsan P, He Z (2013) Hydrogen production in microbial electrolysis cells: choice of catholyte. Int J Hydrogen Energy 38:9619-9624

36. Rozendal RA, Hamelers HV, Rabaey K, Keller J, Buisman CJ (2008) Towards practical implementation of bioelectrochemical wastewater treatment. Trends Biotechnol 26:450-459

37. Torres C, Kato Marcus A, Rittmann B (2007) Kinetics of consumption of fermentation products by anode-respiring bacteria. Appl Microbiol Biotechnol 77:689-697

38. Popat SC, Ki D, Young MN, Rittmann BE, Torres CI (2014) Buffer pKa and transport govern the concentration overpotential in electrochemical oxygen reduction at neutral $\mathrm{pH}$. Chem Electro Chem n/a-n/a

39. Achilli A, Prante JL, Hancock NT, Maxwell EB, Childress AE (2014) Experimental results from RO-PRO: a next generation system for low-energy desalination. Environ Sci Technol 48:6437-6443

40. Straub AP, Yip NY, Elimelech M (2014) Raising the Bar: Increased Hydraulic Pressure Allows Unprecedented High Power Densities in PressureRetarded Osmosis. Environ Sci Technol Lett 1:55-59 
41. Yuan H, Li J, Yuan C, He Z (2014) Facile synthesis of MoS2@CNT as an effective catalyst for hydrogen production in microbial electrolysis cells. Chem Electro Chem 1:1828-1833

42. Phillip WA, Yong JS, Elimelech M (2010) Reverse draw solute permeation in forward osmosis: modeling and experiments. Environ Sci Technol 44:5170-5176
43. Pinto RP, Srinivasan B, Manuel MF, Tartakovsky B (2010) A two-population bio-electrochemical model of a microbial fuel cell. Bioresour Technol 101:5256-5265

44. Logan BE, Hamelers B, Rozendal R, Schröder U, Keller J, Freguia S et al (2006) Microbial fuel cells: methodology and technology. Environ Sci Technol 40:5181-5192

Submit your next manuscript to BioMed Central and take full advantage of:

- Convenient online submission

- Thorough peer review

- No space constraints or color figure charges

- Immediate publication on acceptance

- Inclusion in PubMed, CAS, Scopus and Google Scholar

- Research which is freely available for redistribution

Submit your manuscript at www.biomedcentral.com/submit 